\title{
Biopsy of Mucosa
}

National Cancer Institute

\section{Source}

National Cancer Institute. Biopsy of Mucosa. NCI Thesaurus. Code C51922.

Removal of mucosal tissue for microscopic examination. 